\title{
Isolated Angiitis of the Central Nervous System in Childhood
}

\author{
D.G. Matsell, D.L. Keene, C. Jimenez and P. Humphreys
}

\begin{abstract}
Isolated angiitis of the central nervous system, a rare inflammatory condition of the nervous system, characterized by vasculitis of the small vessels, has not, to the best of our knowledge, been described in childhood. It usually presents with a diversity of neurological symptoms in the fifth to eighth decades of life. We reviewed the case of an 8 year old male with autopsy proven isolated cerebral angiitis, to encourage the consideration of this disorder in children; and to emphasize the lack of sensitivity of present modalities of neurological investigation in the diagnosis.

RÉSUMÉ: Angéite isolée du système nerveux central chez l'enfant L'angéite isolée du système nerveux central, une affection inflammatoire rare du système nerveux, caractérisée par une vasculite des petits vaisseaux, n'a jamais, au meilleur de notre connaissance, été décrite dans l'enfance. Elle se présente avec divers symptômes neurologiques entre la cinquième et la huitième décade de vie. Nous avons revu le cas d'un jeune garçon de 8 ans avec angéite cérébrale isolée prouvée à l'autopsie, pour inciter les cliniciens à considérer cette maladie chez les enfants et pour souligner le manque de sensibilité des modalités actuelles d'investigation neurologique dans ce diagnostic.
\end{abstract}

Can. J. Neurol. Sci. 1990; 17:151-154

Isolated angiitis of the central nervous system is a rare vasculitic process involving only the small vessels of the brain. There have been approximately 36 histopathologically confirmed cases since 1922.1

The clinical spectrum of the disease has been well described by several authors, and the majority of the cases have occurred in the fifth to eighth decades of life. $1-5$ We present the case of an eight year old boy with post-mortem confirmation of this disorder. This case expands our understanding of the clinical spectrum of the disease, in that, to the best of our knowledge, he is the youngest case described, his clinical course was complicated by recurrent intracerebral bleeds, and his investigations included the use of magnetic resonance imaging.

\section{Case Report}

B.D. was an eight year old boy, previously well, who was admitted to the Children's Hospital of Eastern Ontario with a three month history of left sided facial weakness, intermittent medial deviation of his left eye associated with diplopia, head tilt to the right, and occasional frontal headaches. He had an essentially unremarkable past medical history with no family history of significant illness.

His initial physical examination revealed an inability to abduct the left eye, adducting nystagmus of the right eye, left facial asymmetry with droop, deceased sensation to light touch and, temperature on the right side of the face, and subtle heel-toe dysmetria. A tentative diagnosis of a posterior fossa brain tumor was made.

Initial investigations included a complete blood count with differential, serum urea, creatinine, electrolytes, calcium, SGOT, total protein, albumin, sedimentation rate, immunoglobulin and complement levels, and urinalysis - all which were within normal limits. Antinuclear antibodies and a lupus cell preparation were negative. A skull radiograph, chest radiograph, and nuclear brain scan were all normal. An electroencephalogram showed nonspecific changes and brainstem auditory evoked responses demonstrated a disturbance in the upper pons and midbrain. A CT scan (Figure 1) revealed multiple enhancing lesions throughout the cerebrum. A lumbar puncture yielded cerebrospinal fluid with a normal cell count, protein and glucose content, normal $\operatorname{lgG}$ level, absent oligoclonal bands, and negative examination for viruses. bacteria and fungi.

A magnetic resonance scan was performed, demonstrating multiple hyperintense foci predominantly in the white matter of the brainstem, cerebellum and cerebral hemispheres (Figure 2 and Figure 3 ).

He was discharged home with the diagnosis of multiple sclerosis on prednisone $60 \mathrm{mg}$ daily which was tapered over six week period.

He was readmitted 4 months later after the acute onset of severe head pain followed by an inability to move his limbs or speak, although he was fully alert. On physical examination he had an absent gag reflex, eye movements were limited in all directions, and he was quadriparetic with diffuse hypertonia and hyperreflexia. Repeat CT scan revealed a significant pontine hemorrhage. Cerebral angiography revealed no obvious abnormalities, in particular, absence of areas of arterial stenosis and ectasia.

A craniotomy was performed and the brainstem hemorrhage was evacuated. A biopsy of the arachnoid tissue done intraoperatively showed non-specific small vessel perivascular cuffing with mononuclear cells. Postoperatively he had two recurrences of intracerebral bleeding. He was discharged home with the diagnosis of central nervous system vasculitis on oral prednisone and cyclophosphamide.

He was readmitted to hospital seven months later with severe behaviour problems, mood swings, personality changes, and deteriorating school performance. He subsequently developed seizures, for which he received Tegretol.

From the Department of Pediatrics, Neurology Service, and Department of Pathology, Children's Hospital of Eastern Ontario, University of Ottawa, Ottawa

Received July 5, 1989. Accepted in final form October 12, 1989

Reprint requests to: Dr. Daniel L. Keene, Children's Hospital of Eastern Ontario, Neurology Service, 401 Smyth Road, Ottawa, Ontario, Canada KIH 8LI 
He was again discharged from hospital, and 18 months after his initial presentation he was brought to the Emergency Department in refractory status epilepticus; he developed cardiac arrest and died.

\section{Pathology}

The brain weighed 1,420 grams. Gross examination showed prominent meningeal congestion, mild cerebral oedema without significant herniation and a small perichiasmatic subarachnoid hemorrhage. On serial sectioning of the brain, multiple, small, grey-brown plaque-like or streak lesions were observed within the cerebrum, brainstem and cerebellum but absent in the spinal cord parenchyma. The cerebral lesions were predominantly subcortical with multifocal extension into the overlying grey matter, some in the centrum semiovale and a few in the paraventricular white matter. Small foci of recent or old hemorrhages were recognized in several of these lesions. A hemosiderin-stained, $0.7 \mathrm{~cm}$ cystic lesion surrounded by gliosis was identified in the right temporal lobe, involving both cortical grey and white matter but sparing the adjacent thalamolenticular nuclei. The lateral and third ventricles were moderately dilated. Marked tissue loss with cyst formation, hemosiderin discoloration and reactive gliosis occupied a large portion of the dorsal pons and multifocal small grey-brown lesions were noted at the base. The midbrain and medullary lesions were grossly inconspicuous. Plaque-like lesions were, likewise, seen grossly in the cerebellar centrum medullare but not in the cortex.

Microscopic examination showed a small vessel vasculitis/perivasculitis which was limited to the brain and spinal cord. Leptomeningeal vascular involvement was focal in distribution and was not related to superficial or deep parenchymal lesions. Spinal cord involvement was restricted to the

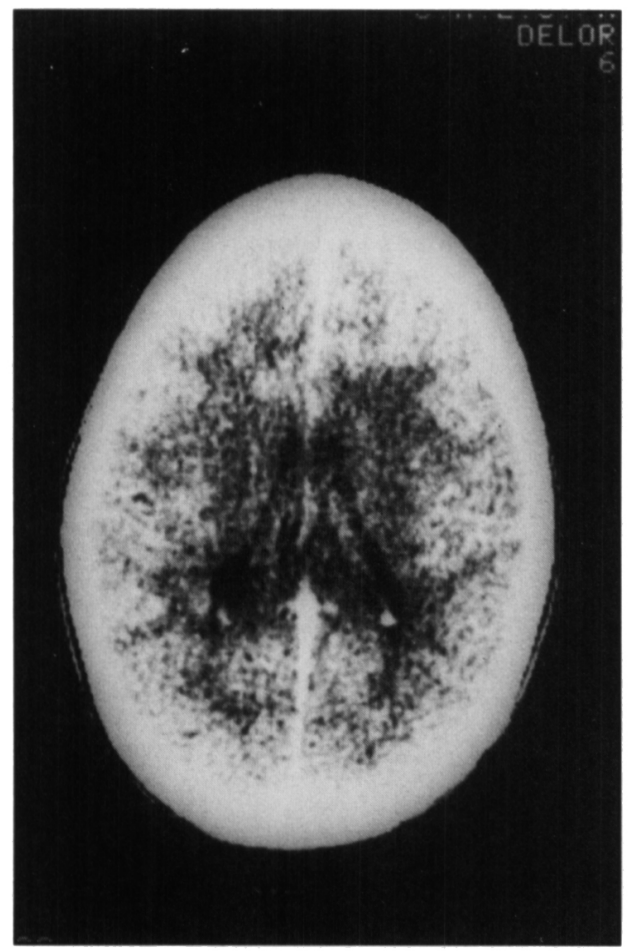

Figure I - Enhanced CT scan demonstrating multiple lesions throughout the cerebrum at initial presentation.
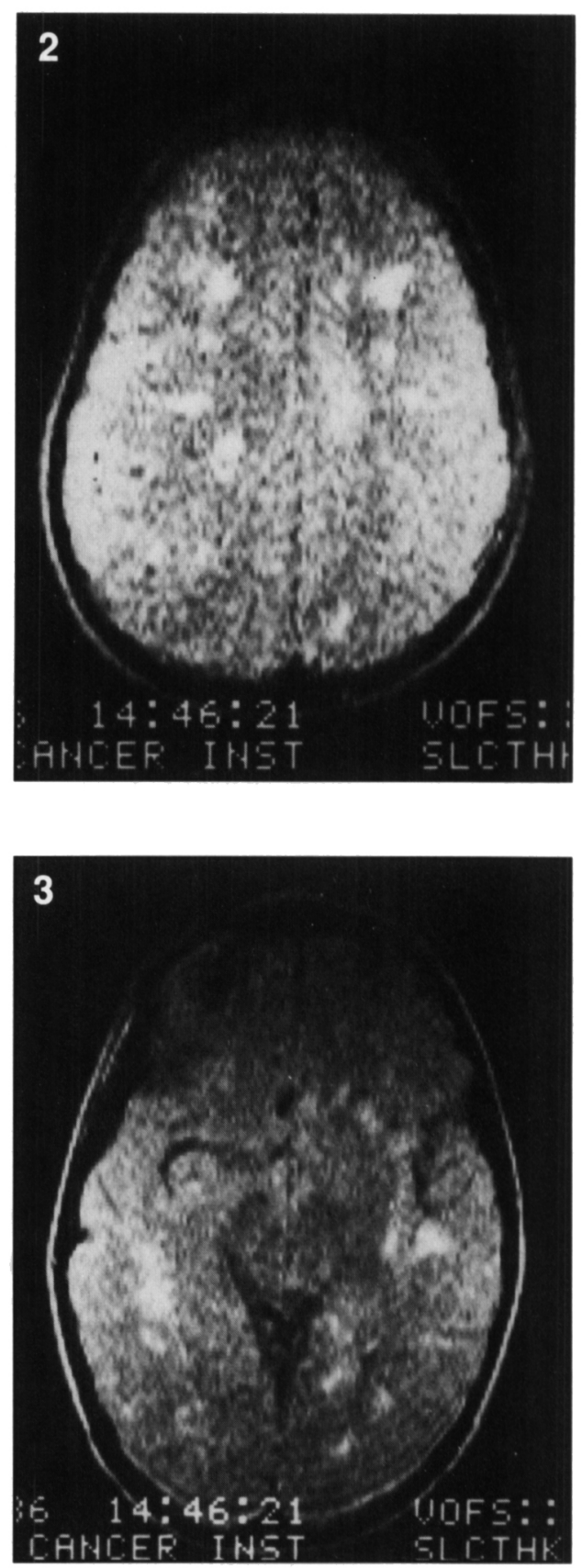

Figure 2 and Figure 3 - Magnetic resonance scan demonstrating multiple hyperintense foci predominantly in the white matter of the cerebrum.

meninges. Capillaries, venules and arterioles of the cerebral and cerebellar white matter, brainstem, and focally of the cerebral and cerebellar cortical grey matter were affected. Many vessels showed unequivocal infiltration of their wall with non-neoplastic lymphocytes, mononuclear histiocytes and rare plasma cells (Figure 4). Multiple sections through the affected foci revealed the presence of multinucleated giant cells (Figure 5) within and surrounding the wall of a fibrosed pontine vessel, adjacent to an area of previous parenchymal destruction. There were no unequivocal occlusive fibrin thrombi recognized but histological 


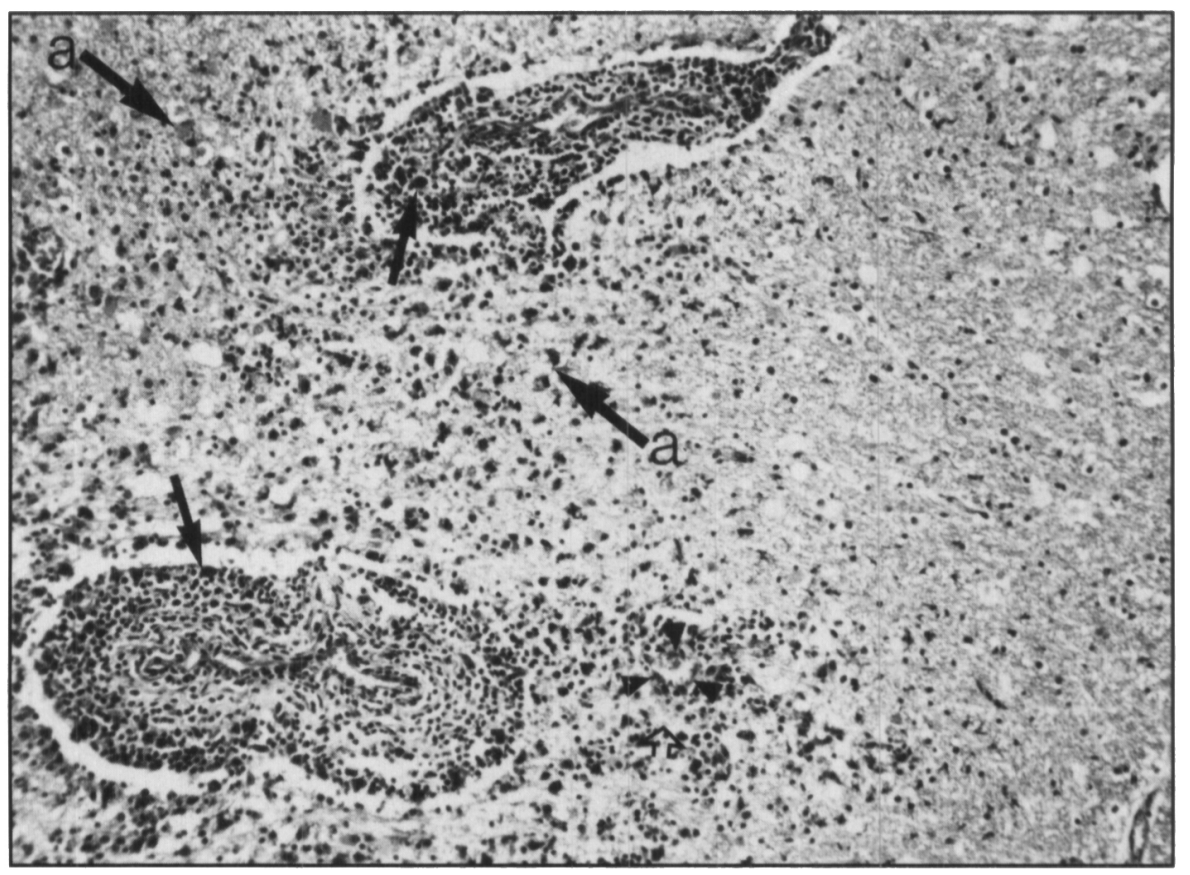

Figure 4 - Marked mononuclear cell infiltrates within and around cerebral vessel walls. Large, dark perivascular cells $(\rightarrow)$, are pigment-laden mononuclear histiocytes. Large cells with a variable amount of cytoplasm $(a+)$ in the adjacent pale and spongy, demyelinated neuropile are reactive astrocytes. Red blood cells (small pale cells designated by $\rightarrow$ ) are seen adjacent to a partially necrotic capillary (outlined by ). Elastic-Masson trichrome stains $x 180$.

stains for fibrin revealed focal deposition of material exhibiting the tinctonial property of fibrin along the endothelial surface and/or within the wall of some vessels. Extravasated red blood cells were observed adjacent to partially necrotic vascular walls. The grossly identified plaque-like or streak lesions corresponded to microscopic foci of vasculitis/perivasculitis, adjacent recent or old hemorrhage, tissue destruction and reactive astrocytic reaction. The cortical cerebral lesions were healed or healing hypoxic-ischemic foci. Vessels outside the nervous system were spared. The pathologic diagnosis was isolated vasculitis of the central nervous system.

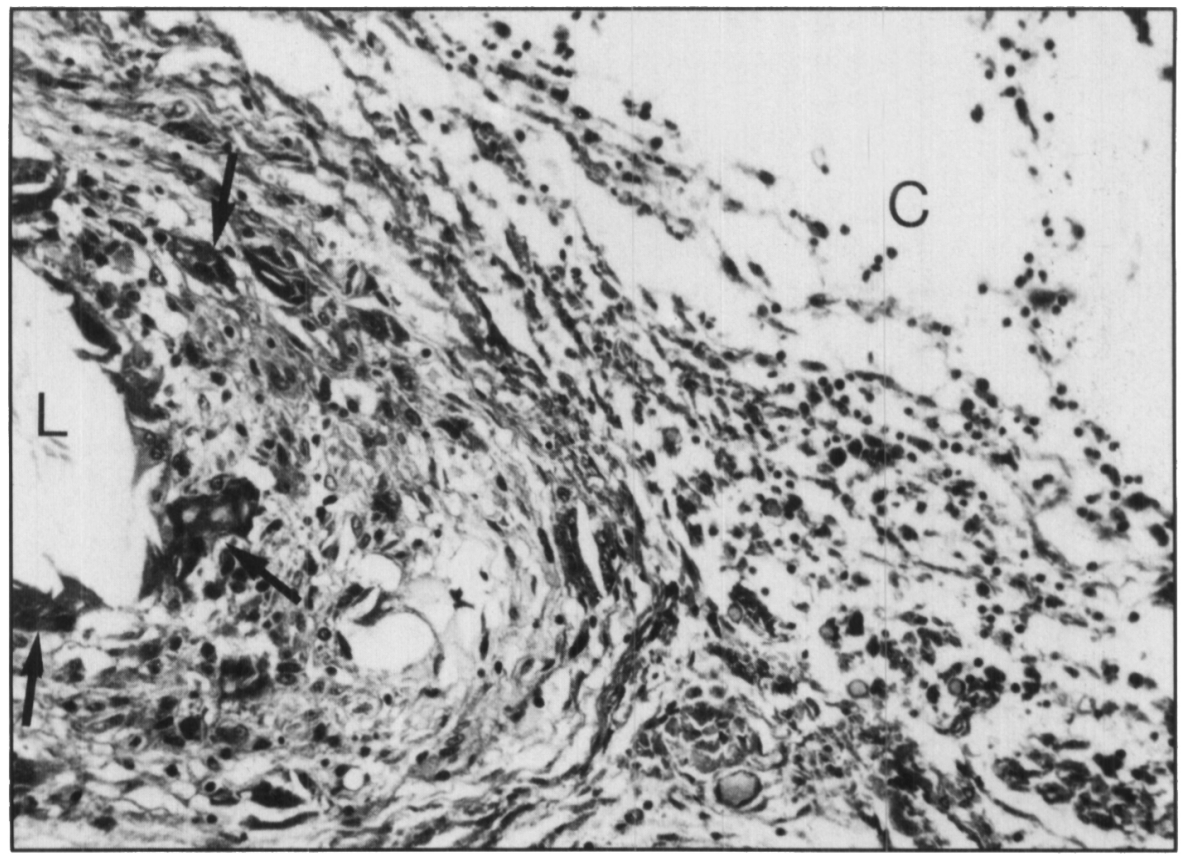

Figure 5 - Fibrosed pontine vessel exhibiting multinucleated giant cells $\rightarrow$ ) in the wall. The vessel is adjacent to a cavitated area $(C)$. L indicates vascular lumen. Elastic-Masson trichrome $\operatorname{stain} \times 275$. 


\section{Discussion}

Since the first case description by Harbitz in $1922^{6}$ and its classification as a separate clinical entity by Cravioto and Feigin in 1959,7 the clinical spectrum of isolated angiitis of the central nervous systems in adults has been well described. The clinical manifestations of the disease are unknown in the pediatric population. Unfortunately, our case was diagnosed post-mortem; nonetheless, his clinical presentation was consistent with previous descriptions from the adult literature.

His initial symptoms and physical findings included cranial nerve palsies, sensory deficits and cerebellar signs, without alteration of his sensorium. Although non-diagnostic, these findings have been previously noted in adult case reports. The progression of his disease was typically relentless resulting in death within eighteen months of presentation. Somewhat atypical in this course was the feature of recurrent intracranial bleeds, reported previously by Clifford-Jones et al in a 43 year old patient.8

We established the diagnosis of isolated angiitis of the central nervous system at autopsy, by demonstrating the typical small vessel vasculitis restricted to cerebral and spinal cord vessels, the presence of a mononuclear infiltrate with occasional giant cells, and the absence of any systemic disease.

We present this case not only to extend the spectrum of the disease into the pediatric age group, but also to re-emphasize the lack of sensitivity, specificity, and inconclusiveness of our modalities of investigation. The results of his immunologic work-up and analysis of his cerebrospinal fluid were completely normal. A CT scan of his brain, at the time of presentation demonstrated diffuse non-specific lesions of the cerebrum. Magnetic resonance imaging revealed diffuse plaque-like foci of hyperintense imaging, but failed to establish the definitive diagnosis of isolated angiitis. While some authors argue that angiographic findings of segmental narrowing of the cerebral vessels permits the ante-mortem diagnosis of the condition, $4,9,10-13$ the lack of sensitivity of this procedure, $8,14-16$ and undetermined specificity preclude its screening diagnostic value.

Other authors ${ }^{4.16-18}$ maintain that the ante-mortem diagnosis of isolated angiitis of the central nervous system should be confirmed by a brain biopsy. This invasive undertaking suffers from a similar lack of sensitivity ${ }^{14.18-21}$ due to sampling errors; however, coupled with a leptomeningeal biopsy its diagnostic value improves.

If we exclude those cases associated with underlying primary diseases and those not confirmed by a tissue diagnosis, the clinical course and prognosis of this entity has been uniformly dismal, with or without treatment with few exceptions. 1,8,22,23 There is some suggestion in recent case reports' that treatment with prednisone and cytotoxic agents improves morbidity and mortality. In our case, an attempt was made to treat with immunosuppressive therapy, but without success. As in most other cases, our patient's course was one of progressive deterioration and death within eighteen months of presentation.

In conclusion, isolated angiitis of the central nervous system, an uncommon clinicopathological entity, remains a diagnostic and therapeutic enigma. Historically, a disease of adulthood, it now has been shown to occur in the pediatric population. As in the adult form of the disease, the diagnostic modalities of CT scan, magnetic resonance imaging, cerebral angiography, and cerebral biopsy, have been shown to lack in sensitivity. The lack of response to immunosuppression in our pediatric patient highlights the malignant course of the disease as described in previous adult case reports.

\section{REFERENCES}

I. Calabrese LH, Mallek JA. Primary Angiitis of the Central Nervous System. Medicine 1988; 67: 20-39.

2. Nuricks S, Blackwood W, Mair WGP. Giant Cell Granulomatous Angiitis of the Central Nervous System. Brain 1972; 95: 133 142.

3. Vincent FM. Granulomatous Angiitis (ed). N Engl J Med 1977; Feb 24,452 .

4. Cupps TR, Moore PM, Fauci AS. Isolated Angiitis of the Central Nervous System. Am J Med 1983; 74: 97-105.

5. Launes J, livanainen $M$, Vuorialho $M$, et al. Isolated Angiitis of the Central Nervous System. Acta Neurol Scand 1986; 74: 108-114.

6. Harbitz F. Unknown forms of arteritis with special reference to their relations to syphilitic arteritis and periarteritis nodosa. Am J N Sc 1922; 163: 250.

7. Cravioto H, Feigin I, Noninfectious granulomatous angiitis with a predilection for the nervous system. Neurology 1959; 9: 599609.

8. Clifford-Jones RE, Love S, Gurusinghe N. Granulomatous angiitis of the central nervous system: a case with recurrent intracerebral hemorrhage. J Neurol Neurosurg Psychiatry 1985; 48: 10541056.

9. Bettoni L, Varra $G$, Bortone $E$, et al. Isolated benign cerebral vasculitis. Acta Neurol Belg 1985; 84: 161-173.

10. Michel D, Vial C, Antoine JC, et al. Angiopathie cerebrale aigue benigne. Rev Neurol (Paris) 1985; 141; 12: 786-792.

11. van Calenberg F, vandenBergh V, Wilms G. Benign isolated arteritis of the central nervous system. Clin Neurol Neurosurg 1986; 88-4: 267-273

12. Snyder BD, McClelland RR. Isolated benign cerebral vasculitis. Arch Neurol 1978; 35: 612-614.

13. Craven RS, French JK. Isolated angiitis of the central nervous system. Ann Neurol 1985; 18: 263-265.

14. Hinck VC, Carter CC, Rippey JG. Giant Cell (Cranial) Arteritis Am J Roent Radium The Nuc Med 1964; 92(4): 769-775.

15. Hughes JT, Brownell B. Granulomatous giant celled angiitis of the central nervous system. Neurology 1966; 16: 293-298.

16. Jellinger K. Giant cell granulomatous angiitis of the central nervous system. J Neurol 1977; 215: 175-190.

17. Griffin J, Price DL, Davis L, et al. Granulomatous angiitis of the central nervous system with aneurysms on multiple cerebral arteries. Trans Am Neurol Assoc 1973; 98: 145-148.

18. Harrison PE. Granulomatous angiitis of the central nervous system. J Neurol Sci 1976; 29: 335-341.

19. Budzilovich GN, Feigin I, Seigel $H$. Granulomatous angiitis of the nervous system. Arch Pathol Lab Med 1963; 76: 250-256.

20. Kolodny EH, Rebeiz JJ, Cariness VS, et al. Granulomatous angiitis of the central nervous system. Arch Neurol 1968; 19: 510-524.

21. Scully RE (ed). Case Records of the Massachusetts General Hospital (Case 35-1985). N Engl J Med 1985; 276: 566-575.

22. Bersford HR, Hyman RA, Sharer L. Self-Limited Granulomatous Angiitis of the Cerebellum. Ann Neurol 1979; 5: 490-492.

23. Kattah JC, Cupps TR, DiChiro G, et al. An unusual case of central nervous system vasculitis. J Neurol 1987; 234: 344-346. 